\title{
Publication: in whose interests?
}

'The attribution of the phrase: 'the pen is mightier than the sword' is rife on wikipedia. Some observers claim the original idea came from the bible whilst others link it back to medieval writers, Shakespeare or Burton (Whetstone, 1582; Shakespeare, 1602; Burton, 1621). The actual phrase is attributed to Edward Butler Lytton and appeared in his play entitled Richelieu; or the Conspiracy. What ever the origin, we intuitively understand the meaning: there is power in writing made more so by the attribution we give to something that appears in print.

This means that when something goes to academic press the publishers have made every reasonable effort to ensure the quality of that publication. To ensure this, the manuscript would have gone through a rigorous process to assess a number of factors including transparency, authorship, originality and integrity of the work. Readers initially base their assessment on the peer review process and then undertake their own critical assessment. Authors trust that the editors will provide fair scrutiny by appointing appropriately experienced peer reviewers. Peer reviewers expect the editors to provide a balanced appraisal where a difference of opinion arises, and to provide guidance and support when needed, to facilitate their assessment of a manuscript. The publishers trust the editors to ensure that best practice and publication ethics are observed. The academic/professional societies for whom the journal is published appoint the editors based on their profile and faith that they will deliver the operational vision and philosophy of the journal. The governance arrangements to ensure this is in place, requires there to be an advisory board/editorial panel who meet regularly to monitor performance and offer recommendations on how the journal might develop to meet the needs of the readership, the profession and contribute to the dissemination of knowledge. In the case of Nursing in Critical Care, this is about advancing knowledge that informs critical care nursing practice. Therefore, what is published has the power to transform what we do and that is why it is considered mightier than the sword. As with any battle there is so much more at stake. Who gets to write where and what happens as a consequence of that is profoundly important. In this editorial, I aim to set out the main contemporary drivers and how this affects what gets published.

First, there is the audience. The audience for an academic journal is now international. The traditional audience, determined by who could access paper copy has been transformed. The World Wide Web means that anyone can download manuscripts. As a consequence who writes for the journal shifts as much as who reads it. Contributors provide knowledge that opens new opportunities for understanding through the comparison of international data, practice developments and reviews with our own. This should generate debate, practical guidance and change.

The quality of work is also assessed by external agencies. These include impact factor (IF) of a journal and ultimately how this can be assessed through the research excellence framework (REF). The significance of both these systems for measuring quality will be outlined to help explain the impact this has on the generation of new knowledge and how that is disseminated through publication.

\section{IMPACT FACTOR}

An IF is an indicator of quality and a proxy measure of the importance of the journal in the field. A journal is awarded an IF based on the average number of citations per paper published in the preceding 2 years. This excludes letters and editorials. These statistics are calculated by indexing agencies, and in the case of IF, Thomson-Reuters Institute of Scientific Information (ISI) (Thomson Reuters, 2011). The top 10 journals ranked by impact for nursing are number one: International Journal of Nursing Studies (IF, 2.31) with The Journal of Clinical Nursing ranked tenth (IF 1.38) (Science Watch, 2010). Nursing in Critical Care was indexed from August 2011 which means that a review of the citations of publications in 2009-2010 will result in our IF. This will be announced in the summer of 2012.

Citation is highly discipline specific so one can see wide variation in the IF awarded. For example, The Lancet has an IF of 33.63 (2010 Journal Citation Reports ${ }^{\circledR}$, Thomson Reuters, 2011) but Nature, one of the highest ranking journals has an IF of 36.101 in 2010 (Thomson ISI). These two journal demonstrate the general rule that the broader the readership, the higher the IF. Obviously citations in areas of high specialism have, by necessity, a high degree of overlap between authors and readers and this can lead to a lower citation rate within a discipline, but does not necessarily reflect poor quality although it would reflect a lower IF. Nursing journals tend to have lower IF because the nature of the publications are so broad and serve clinicians who might be studying to inform their practice but not necessarily be publishing their own research and citing others in their field.

To boost the IF of a journal, editors might favour submissions that are likely to have a high citation, for example, review articles, and view less favourably case reports and audits. Conversely, authors might be less likely to publish a case study because they 
feel this would get fewer citations so editors do not have this material to publish. The cycle is self-perpetuating, but it does mean that a valuable source of knowledge exchange does not get into print unless actively pursued or commissioned by the editorial board.

The IF of a journal does have a direct impact on who decides to publish what and where. Authors will decide to publish where they can be assured a higher number of citations and where the audience that needs to read their results is most likely to look. Fundamentally, this will also affect prestige, income generation and reputation for authors and indirectly, their employers. Polit and Northam (2011) go further suggesting that the IF of a journal can even influence 'scholarly pursuits'. While Ketefian et al. (2010) raise the issue that some international researchers, for whom English is not their first language, are faced with the additional challenge of publishing the results of government funded research in high IF journals published in English. The suggestion is that a high IF reflects the methodological rigour of the work and in this instance the higher the IF the greater the confidence for the reader in the quality of that work. However, this does not address the dilemma that most authors face when deciding where to publish their article: to comply with their organisations' need for high impact or disseminate their findings more widely by publishing in journals with lower impact ratings but read by clinicians.

So why does this all matter? What impact does this have for clinicians? Why is this relevant to practice? There are a number of issues that need to be addressed to answer these questions namely how these systems can affect what is researched and what is published. The REF is a significant event that can shape what is researched, who gets funding to do it and helps to define what is considered to be highquality research. It also significantly influences what is termed 'impact fever'
(Polit and Northam, 2011), the quest for researchers to get their work published in the highest rated journals so they can get higher REF ratings. This might have meant that clinicians would not immediately access research published in these journals unless translated into news reports in 'coffee table' professional weekly journals. However, recent changes to the REF now mean that researchers have to demonstrate the impact of their work and this creates new challenges that will influence publication decisions. Sadly, this issue is not resolved simply by publishing the article in two journals for two different audiences. This practice constitutes a breach of publication ethics and is termed 'redundant publication' (see Editors' Note).

\section{THE REF}

The REF is a system established by the Higher Education Funding Council for England (HEFCE) to assess the quality of research undertaken by researchers based in Universities. The purpose of the REF is to drive up quality, benchmark research against international competitors, and to ensure funding goes to centres of excellence wherever they are found. Submission is made to units of assessment and the nursing submissions go into Unit 3 along with dentistry, allied health professions and pharmacy (HEFCE, 2010).

This system is based on peer review of a portfolio of work by an individual researcher. The researcher submits up to four pieces of work (invariably articles) for assessment. Researchers whose work has met the threshold determined by their School, Faculty and University submit their work along with their colleagues to their unit of assessment. Based upon that unit of assessment, Universities are awarded funding to support their research initiatives. The outcome of this exercise will be announced in Spring 2015.

The REF makes publishing a highly political exercise. The IF of the journal where the submitted work for assessment is placed is a factor in determining the quality of the output by the REF reviewer. It has been estimated that some peer-reviewing panelists may be confronted with up to 700 publications each to assess (Dunleavy, 2011). Important decisions will need to be made on a vast amount of data, therefore any factor that can influence the judgment of the assessor will be important and the IF of any journal is a significant variable in determining the quality threshold for that work. In preparation for the REF, authors become very savvy about where to place their work to gain the greatest credit. This contributes to the 'impact fever' described earlier (Polit and Northam, 2011).

The REF is an important assessment to ensure public money is being spent appropriately, but has been criticized as being burdensome, bureaucratic and time consuming (Dunleavy, 2011). Indeed the last exercise known as the research assessment exercise (RAE) was estimated to have cost $£ 56.7$ million, $0.5 \%$ of the total budget to be allocated on the basis of the results (Bekhradnia, 2009). Nevertheless, this is a frightening large sum of money dedicated to quality assurance processes (although PA consulting who worked out these figures for direct cost of the exercise to HEFCE and indirect cost to the University declared this to be cost saving because research councils were estimated to spend $20 \%$ of their budget on former quality assessment processes). The next round of assessment, known as the REF is due to happen in 2014 with December 2013 being the end of publication in this census (HEFCE, 2011).

Universities are already engaged in exercises to amass information and generate case studies to demonstrate the impact of their research. The nature of the exercise shapes activity within the Universities and the type of research the academics do (Bekhradnia, 2009) because the REF is linked so strongly to reputation and careers can be made or broken as a consequence. You 
might hear your academic colleagues bemoaning the time and effort this takes that might otherwise be dedicated to teaching and learning and indeed research and publication or time in clinical practice. The REF certainly concentrates the mind on how research fits into the portfolio of activity undertaken by any centre and it does inform strategic direction and career trajectories.

One aspect that is assessed is the amount of income the researcher generates as this is seen as a crude measure of the quality of their research because (i) it has been quality assured to gain the funding, (ii) the grant was won in open competition implying it was better than the rest and (iii) that the work would have been subject to strict research governance arrangements. This does not however take into account the political vagaries of funders nor the fact that those with a reputation are funded. This makes breaking into the circle incredibly difficult for newcomers. Further that specific methodologies and tried and tested approaches (and indeed researchers) tend to gain funding especially where the proposed research addresses a topic that fits the public mood or political agenda. This can have two effects. First, specialist areas like critical care might receive less money to support research when other agendas are given priority. Second, research that is funded tends to be a low risk to the funder. Innovation, challenge and contribution might feature in the headline calls for proposals, but the reality might be that conservative proposals get funding. This can potentially create an intellectual recession despite all the rhetorical claims that funding excellence is intended to do quite the reverse. In summary, the system determines what gets researched by whom and this can have a direct impact on the generation of new knowledge for critical care practice.

For the first time, the REF requires academics to make a case for impact of their research. Where else might we see impact other than in practice?
Yet articulating with assurance that the research undertaken has directly impacted upon practice or, in the longer term, patient outcome is problematic. Clearly, scientific research has a much better chance of making such a case, first because science is about the attribution of cause and effect and second, because the type of work undertaken in that paradigm is more likely to be very specific. This model is particularly alarming for researchers for whom claims of impact are far more tenuous because of the multitude of other variables that could create an effect. This is made even more ironic where the philosophical underpinnings of the work would result in reservation in making such a claim. Set beside experimental research conducted by pharmacists or dentists, qualitative work might come off badly when attempting to directly attribute the impact of the work on patient outcome. Of greater concern, any methodology should be shaped by the original research question, but these approaches to auditing and quality assurance systems ultimately determine what type of new knowledge is generated. Measuring impact was introduced with the express purpose to assure that money allocated to research from the public purse was well spent. Ironically, it might serve to engineer the behaviour of nurse researchers toward research that has 'impact' and 'visibility' and omit other types of research that has relevance to the communities of patients and professionals they serve.

\section{CONCLUDING REMARKS}

Professional journals provide a repository of new knowledge to inform developments in practice and advance thinking. It is essential they remain accessible to clinicians. Journals only thrive where this is sufficient copy submitted for review. The number and type of manuscripts submitted to a journal acts as a barometer of the amount of research and development that is going on in the field, but it is also subject to other variables and systems that determine where authors decide to publish what material.

Publishing is highly political because it ultimately affects decisions over research funding in the future. A researchers' $\mathrm{CV}$, including their publication record, is an important factor in determining funding awards. The publication portfolio submitted for REF assessment is rated but funding will be directed to units where the overall rating is 'international' or 'world leading'. The label is selffulfilling because units with higher ratings attract more funding, research degree students and ultimately highquality researchers working in them. But what those high-quality researchers ultimately research is informed by funding streams. Keeping critical care on the map for future funding is essential to ensure our practice is based on the latest evidence. Doing that requires researchers to publish in the field and determine areas for future research.

Ideally, a journal will offer a wide and diverse mix of papers for their readers ranging from the theoretical and complex to the practical and clinical. Journals such as Nursing in Critical Care continue to serve the BACCN membership. The BACCN membership reflects a broad range of academics, managers and clinicians working in critical care but it also has a responsibility to other international readers. The journal has to continue to attract the highest quality papers and ensure they go through the rigorous reviewing processes. The editorial board provides the governance to the editorial team to ensure that the journal remains true to its philosophy whilst meeting all the needs of its readers and authors.

Critically, despite all the measures that are set in place to ensure rigour and quality, it is beholden to the reader to review, critique and assess the papers to determine suitability and applicability back to their own practice environment. Nursing in Critical Care will continue to 
be a professional journal that provides the range of papers that can inform practice and ultimately impact upon the patients for whom they care. The 'pen is mightier than the sword' but the systems that shape what is written should not go underestimated.

\section{Julie Scholes Co-editor, Nursing in Critical Care}

\section{REFERENCES}

Bekhradnia B. (2009). Proposals for the research excellence framework - a critique. www. hepi.ac.uk/.../43\%20Proposals $\% 20$ for $\% 20$ the $\% 20$ REF\%20-... (accessed 14/11/11).
Dunleavy P. (2011). The research excellence framework is lumbering and expensive. For a fraction of the cost, a digital census of academic research would create unrivalled and genuine information about UK universities' research performance. http://blogs. lse.ac.uk/impactofsocialsciences/2011/06/ 10/ref-alternative-harzing-google-scholar/ (accessed 14/11/11).

HEFCE. (2010). Units of assessment and recruitment of expert panels. http://www.hefce. ac.uk/research/ref/pubs/2010/01_10/ (accessed 14/11/11)

HEFCE. (2011). Research excellence framework REF 2014 timetable. http://www.hefce.ac. uk/research/ref/timetable/(accessed 14/ 11/11).

Ketefian S, Dai Y, Hanucharunkul S, Mendes I, Norman I. (2010). Environments for nursing scholarship and journal impact factor in five countries. International Nursing Review, 57: 343-351
Polit D, Northam S. (2011). Impact factors in nursing. Nursing Outlook, 59: 18-28.

Science Watch. (2010). Sci bytes - what's new in research journals ranked by impact factor Sci bytes 03.28.2010. http://sciencewatch. com/dr/sci/10/mar28-10_1/(accessed 14/ $11 / 11)$.

Thomson-Reuters. Journal citation reports. http://thomsonreuters.com/products_ services/science/academic/(accessed 14/ 11/11).

Whetstone G. (1582). Heptameron of civil discourses. The dashe of a Pen, is more greevous than the counterbuse of a Launce. http://www.phrases.org.uk/meanings/ the-pen-is-mightier-than-the-sword.html.

Shakespeare W. (1602). Hamlet. Many wearing rapiers are afraid of goose-quills and dare scarce come thither.

Burton R. (1621). The anatomy of melancholy. From this it is clear how much more cruel the pen may be than the sword.

Editors' Note: Redundant (multiple) publication

The Editors of Nursing in Critical Care would like to make clear their position on redundant publication. Wiley-Blackwell has produced Best Practice Guidelines on Publication Ethics and their position, which the Editors support, is reproduced here:

Best Practice: Redundant (multiple) publication

Abstracts and posters at conferences, results presented at meetings (for example, to inform investigators or participants about findings), results databases (data without interpretation, discussion, context or conclusions in the form of tables and text to describe data/information where this is not easily presented in tabular form) are not considered by Blackwell Publishing to be prior publication.

Journals may choose to accept (i.e. consider 'not redundant') the re-publication of materials that have been accurately translated from an original publication in a different language. Journals that translate and publish material that has been published elsewhere should ensure that they have appropriate permission(s), should indicate clearly that the material has been translated and re-published, and should indicate clearly the original source of the material. Editors may request copies of related publications if they are concerned about overlap and possible redundancy. Re-publishing in the same language as primary publication with the aim of serving different audiences is more difficult to justify when primary publication is electronic and therefore easily accessible, but if editors feel that this is appropriate they should follow the same steps as for translation.

Editors should ensure that sub-group analyses, meta- and secondary analyses are clearly identified as analyses of data that have already been published, that they refer directly to the primary source, and that (if available) they include the clinical trial registration number from the primary publication.

The Blackwell Publishing Exclusive License Form, the OnlineOpen Form, or the Copyright Assignment form, one of which must be submitted before publication in any Blackwell journal, requires signature from the corresponding author to warrant that the article is an original work, has not been published before and is not being considered for publication elsewhere in its final form either in printed or electronic form.

Reproduced with kind permission from John Wiley \& Sons.

First published in the International Journal of Clinical Practice:

Graf, C., Wager, E., Bowman, A., Fiack, S., Scott-Lichter, D. and Robinson, A. (2007), Best Practice Guidelines on Publication Ethics: a Publisher's Perspective. International Journal of Clinical Practice, 61: 1-26. doi: 10.1111/j.1742-1241.2006.01230.x 